\title{
Wilson Harris's Multi-Faceted and Dynamic Perception of the Imaginary ${ }^{1}$
}

\section{HENA MAES-JELINEK}

\section{The birth of the imagination is infinite}

What are the tasks of imaginative genius to begin the transformation of $[\ldots]$ barriers in the light of [...] unsuspected resources available to the Imagination within the abyss of our late twentieth-century age?

\section{$\mathrm{M}$}

OST OF WILSON HARRIS'S FICTION and essays concentrate on the role of the imagination in the existential process he re-creates or comments on. As he wrote in an unpublished essay, "The Key word for me as a writer is imagination." ${ }^{4}$ One may therefore ask what he means by the word apart from its obvious definition as a creative faculty. Another question is: in what sense can he be called a "warrior" of the imaginary? As their titles indicate, the subject of many of his essays is imagination: "A Talk on the Subjective Imagination"; "Some Aspects of Myth and the Intuitive Imagination"; "Literacy and the Imagination"; "Validation of Fiction: A Personal View of Imaginative truth"; "The Fabric of the Imagination"; "The Unfinished Genesis of the Imagination"; The Radical Imagination; "Imagination Dead Imagine: Bridging a Chasm";

'A slightly different version of this essay was published in Hena Maes-Jelinek, The Labyrinth of Universality: Wilson Harris's Visionary Art of Fiction (Cross/Cultures 86; Amsterdam \& New York: Rodopi, 2006): 517-525.

${ }^{2}$ Wilson Harris, "Wilson Harris Interviewed by Alan Riach," in The Radical Imagination, Lectures and Talks, ed. Alan Riach \& Mark Williams (Liège: L3 - Liège Language and Literature, 1992): 53

Wilson Harris, "The Unfinished Genesis of the Imagination," Temenos Academy Review 13 (1992): 72 .

${ }^{4}$ Wilson Harris, "The Voyaging Imagination (Undreamt-of Resources of Spirit)," unpublished manuscript: 5 . 
"Creolization and the Creative Imagination"; "The Imagination on Trial"; "The Age of the Imagination"; "The Voyaging Imagination"; "Canaima: an Overturning of Habits of Mind in Profoundest Trials of the Imagination"; The Womb of Space: The Cross-Cultural Imagination.

Such obsessive concern testifies to the centrality of this concept in his work, while the variety of titles makes it clear that his definition is neither final nor absolute. It suggests, rather, the partiality of different approaches, in keeping with the author's conviction that all statements are partial, and it also implies that his quest for meaning parallels the evolutionary character of imagination itself.

Already in his first novel, Palace of the Peacock, the first part of The Guyana Quartet, there is a distinct link between injustice and the lack of imagination it denotes. Donne, the conquistador and plantation owner who pursues Amerindians he wants to use as cheap labour, admits: "I grant I have been cruel and harsh [...]. I have treated the folk badly [...]. I am beginning to lose all my imagination." ${ }^{5}$ Nevertheless, exploitation and injustice do not lead to insubordination, for the Amerindians, who are never actually reached, become for Donne spiritual agents of self-confession and repentance. In The Whole Armour, the third part of the Quartet, Cristo is unjustly accused of a crime he has not committed, but he eventually gives himself up to the police and agrees to die, moved by a "force of spiritual resolution," sacrificing himself for the community and achieving a freedom beyond life and death. In The Eye of the Scarecrow, re-creating the Guyana Strike in $1948{ }^{7}$ when some of the strikers were shot dead by the police, the narrator deplores the killing but regrets their "aimless and subversive" action in the name of a dangerous "progressive realism." Harris has always objected to a stance of insubordination and resistance or "politics of protest," which he calls "self-righteous deprivation":

\footnotetext{
${ }^{5}$ Wilson Harris, Palace of the Peacock (1960; London: Faber \& Faber, 1998): 56.

${ }^{6}$ Wilson Harris, The Whole Armour (London: Faber \& Faber, 1962): 111.

The strike lasted four and a half months in eight sugar estates on the east coast of the Demerara in reaction to the system of work from 'cut-and-drop' to 'cut-and load'. On 16 June the police opened fire at a plantation, killing five workers and injuring twelve. On this subject, see Cheddi Jagan, The West On Trial (Berlin: Seven Seas, 1975): 90.

Wilson Harris, The Eye of the Scarecrow (London: Faber \& Faber, 1965): 18.

Wilson Harris, "The Fabric of the Imagination," in From Commonwealth to Post-Colonial, ed. Anna Rutherford (Mundelstrup \& Sydney: Dangaroo, 1992): 19.
}

One's pride then becomes caught up in one's humiliations, one's deprivations [...]. One is proud to maintain a limited, narrow position, and forever to complain to the world of the ways in which one has been oppressed or whatever. The imagination $[. .$.$] has to go very much deeper and find links between what I$ call the occult and the triumphs of love. ${ }^{10}$

In view of such a position, Harris can hardly be called a "warrior," except that his plea for an imaginative renewal is carried out through his writing with the convincing intensity of a passionate advocate of his conception of the imagination.

What does Harris mean by "the occult"? He is referring both to those disregarded by society and by conventional history ${ }^{11}$ and to the unconscious forces within the psyche and the deeper motivations that are often ignored in spite of their influence on human behaviour. He believes that the solution to the world's problems are neither economic nor political, ${ }^{12}$ while in fiction he criticizes the realistic novel or "novel of persuasion," as he calls it, which rests "on grounds of apparent common sense" and takes place "on an accepted plane of society we are persuaded has an inevitable existence." ${ }^{13}$ It doesn't mean that in his own fiction Harris ignores actual reality. His novels are as full of violence and terror as many other Caribbean novels. ${ }^{14}$ Caribbean history lies at the root of all his creations and is the substance of a never-ending quest "through" (a favourite word in his essays) appearances as well as a quest for "windows into reality." ${ }^{15} \mathrm{He}$ also referred to "the intuitive life of the imagination, its spectrality and miraculous concreteness." 16 This is illustrated in The Dark Jester when the narra-

${ }^{10}$ Wilson Harris, "Unfinished Genesis: A Personal View of Cross-Cultural Tradition," in The Radical Imagination, 99. See also "the inner desperation of victim cultures which cemented their deprivations into a perverse royalty of hate," Resurrection at Sorrow Hill (London: Faber \& Faber, 1993): 92-93.

${ }^{11}$ See Wilson Harris, Tradition the Writer and Society (London \& Port of Spain: New Beacon, 1967): 36 .

${ }^{12}$ See Harris, "The Unfinished Genesis of the Imagination," 73.

${ }^{13}$ Harris, Tradition the Writer and Society, 29.

${ }^{14}$ See his treatment of slavery in The Far Journey of Oudin (London: Faber \& Faber, 1961) and The Secret Ladder (London: Faber \& Faber, 1963) as well his re-creation of the Jonestown massacre in Jonestown (London: Faber \& Faber, 1996).

${ }^{15}$ Wilson Harris, "Profiles of Myth and the New World," in Nationalism and Internationalism. (Inter)National Dimensions in Literatures in English, ed. Wolfgang Zach \& Ken L. Goodwin (Tübingen: Stauffenburg, 1996): 81

${ }^{16}$ Harris, "The Unfinished Genesis of the Imagination" (1992), in The Unfinished Genesis of the Imagination, ed. Bundy, 256. 
tor sees "the first work of art [...] in the inner Underworld of the Kings of America. Half-flesh, half-work-of-art. A stretched figure, cruelly placed on a plank, in the belly of a slave-ship."17

The history of the Caribbean is one of dismemberment, slavery, exploitation. Harris calls the victims of history the "eclipsed," the "unborn" or the "uninitiated," 18 and it is the role of the imagination to retrieve them from oblivion, which is actually the subject of his novels. In The Eye of the Scarecrow, which marks a turning-point in his fiction by becoming more philosophical, he refers to the depository of past experience in the unconscious as "it - the accumulative ironies of the past, the virtuous rubbishheap and self-parody of ancestors in death." 19 It was to take many different forms in subsequent novels and, as we shall see, is called by different, original yet related terms.

Unlike other Caribbean writers who asserted in the past that the Caribbean is "historyless" and uncreative, ${ }^{20}$ Harris is convinced that "the void" or sense of void into which the "eclipsed" fell, whether African slaves cut off from their country of origin or Amerindians present though forgotten in his own ancestry, that this void is actually as dense as the landscape he discovered when he led expeditions in the Guyanese jungle. As suggested above, this density is made of the accumulated sufferings of the oppressed, either invisible (like the Amerindians in Palace of the Peacock) or lost in an abyss of unconsciousness. Harris calls this forgotten substance "Absent Presence" fossilized can be revived, as he revives in his fiction an unacknowledged underground tradition, "a living open tradition which realizes itself in an enduring capacity associated with the obscure human person." ${ }^{23}$ Harris calls the receptacle of these "live fossils" "the womb of space," an expres-

\footnotetext{
${ }^{17}$ Wilson Harris, The Dark Jester (London: Faber \& Faber, 2001): 98-99.

${ }^{18}$ Harris, The Eye of the Scarecrow, 83, 103. See also, in the same novel, "The Manifesto of the Unborn State of Exile," 95-106.

${ }^{19}$ Harris, The Eye of the Scarecrow, 56.

${ }^{20}$ Among them V.S. Naipaul. For Harris's comments on Caribbean forms of creative expression, see History, Fable and Myth in the Caribbean and Guianas, intro. Selwyn R. Cudjoe (1970; Wellesley MA: Calaloux, 1995)

${ }^{21}$ Harris, "The Absent Presence: The Caribbean, Central and South America," in The Radical Imagination, 81 .

${ }^{22}$ Wilson Harris, The Womb of Space: The Cross-Cultural Imagination (Westport CT: Greenwood, 1983): xx.

${ }^{23}$ Harris, Tradition the Writer and Society, 36.
}

sion inspired by the dense landscape of the jungle, which conveys its livingness and capacity for renewal. It is both the concrete refuge of hunted Amerindians and Maroons and a metaphor for the repository of neglected history, nevertheless susceptible of rebirth, as "womb" makes clear. Again in keeping with the variety of approaches to this fictional substance, the "womb of space" is designated by different terms such as "spirit," a "deposit of ghosts," 24 the unconscious, "living text,", 25 "otherness," "the sacred," the mythical, the archetypal. Though related, they are not synonymous but different aspects of a wholeness and deep-seated cultural reality towards which Harris's characters move. He also calls it "the submerged territory of the imagination., ${ }^{, 26}$

The way into that submerged territory is through the imagination itself, which is therefore both creative agent and the multi-faceted substance it apprehends. But if that substance makes up a "wholeness," it can never be perceived in its entirety, especially since it keeps evolving, just as the creative agent is always in the making and never complete. Hence Harris's concept of "the unfinished genesis of the imagination," which is also essentially a dynamic process in harmony with the existential flow of "life-indeath and death-in-life" ${ }^{, 27}$ in nature:

I see the environment as a measure of reflection in the person, a measure of the cosmos in the person [...]. We need [...] to scan with subjective eyes landscapes/oceanscapes/riverscapes and the elements within these for complex reflections of absent/present creatures and beings. ${ }^{28}$

We find in this interconnection of landscape and man the rejection of an exclusive anthropocentrism common in Western philosophy, an interconnection which also includes the animal world. Harris repeatedly alludes to Titian's painting of the "Allegory of Prudence" which so eloquently illustrates that connection, also obvious, as he explains, in Pre-Columbian art. This kinship between worlds - natural, human, animal - came to him as a

\footnotetext{
${ }^{24}$ Wilson Harris, The Infinite Rehearsal (London: Faber \& Faber, 1987): 1.

25 "The Landscape of Dreams," interview by Michael Gilkes, in Wilson Harris: The Uncompromising Imagination, ed. Hena Maes-Jelinek (Mundelstrup \& Sydney: Dangaroo, 1991): 33 .

${ }^{26}$ Harris, The Womb of Space, xix.

${ }^{27}$ Harris, Palace of the Peacock, 25.

${ }^{28}$ Wilson Harris, "The Age of the Imagination," Journal of Caribbean Literatures 2.1-3 (2000): 22 .
} 
revelation on his first expedition in the Guyanese interior ${ }^{29}$ and radically changed not just his perception of nature but also of the role of the imagination and, as Fred D'Aguiar puts it, "how he imagined":

This was the beginning of a task I could not evade [...] that lay in the incorporation of shells, of the branches of trees, of wood in oneself like a skeleton interiorly and imaginatively in oneself - as much as exteriorly in diverse and complex nature. ${ }^{30}$

Similarly, in practically all his novels nature is a catalyst of consciousness. To take but one example, in Ascent to Omai Victor, the protagonist, ascends Omai in South Guyana:

Beneath him lay the chasm of the river, volcanic and subdued. Above him stood the mountains of lava, worshipful and brooding, a subsidiary ridge of temperament, thrusting $[\ldots]$ towards loops of sky and bush. Topography of the heartland. Within one such loop [...] the sun appeared to vegetate, hanging in the sky. Suddenly [...] Victor felt himself addressed by a line from a Russian poet - art of revolution - a cloud in trousers [...]. Encircling vestments of poetry - Donne to Mayakovsky. Victor stopped to examine his own conscience in this respect half-metaphysical, half-dialectical. ${ }^{31}$

As a stimulus to consciousness, imagination is essentially an agent of conversion, what Harris called the "cconvertible' property of imagination.",32 In Jonestown the narrator, Bone, who had collaborated with the sect leader, Jones, to set up an experimental community in the Guyanese interior, awakens to his own responsibility towards the "extinct" of the experiment when nearly one thousand people died after being forced to drink a cyanide soup. He borrows from Beckett the title of his narrative or "Dream Book," Imagination Dead Imagine, a motto which captures the process in which he is involved: the gradual transformation of his consciousness into a "Memory Theatre" in which past victims come to life, not just individuals he knew but vanished multitudes including pre-Columbian peoples, who disappeared in apparently dead history. Imagination becomes then the instrument of his moral and emotional awakening: "One must re-imagine death as a live fossil apparition. Imagination Dead Imagine."33.

29 “' When one dreams one dreams alone': Wilson Harris interviewed by Fred D'Aguiar," Bomb 82 (Winter 2002-2003): 75, 76.

30 ." When one dreams one dreams alone'," 76

${ }^{31}$ Wilson Harris, Ascent to Omai (London: Faber \& Faber, 1970), 16-17.

${ }^{32}$ Harris, Tradition the Writer and Society, 52.

${ }^{33}$ Wilson Harris, Jonestown (London: Faber \& Faber, 1996), 232.
Harris's emphasis on convertibility in all aspects of life finds expression in his original language, in particular in his "convertible imageries."34 These are a source of difficulty for some readers but it must be kept in mind that they originate in Harris's suppression of the fixed boundaries between categories of being and of the conventional static frames into which we tend to imprison different forms of life. These convertible imageries abound in the narratives, generating their rhythm and animating a movement in keeping with the flow of life. The most obvious example is in Palace of the Peacock when the sun, initially a symbol of Donne's implacable rule, breaks into stars prefiguring the breakdown of his power and his own transformation. In Companions of the Day and Night the narrator translates into a novel the papers, diaries, paintings and sculptures of his protagonist, "Idiot Nameless" 35 and thinks that "the paintings and sculptures to which the writings related were doorways through which Idiot Nameless moved." 36 But this isn't just a movement through apparently static works of art and towards the origins of creation, these works of art themselves change like the stone statue of an emperor in Mexico turning into "Emperor Rain" and becoming "Emperor Stone Rain.",37 Another example is the "transubstantiation of bone into rain" 38 (the solid becoming fluid) that Sister Rose envisions. Related to such conversion is the mutability of the senses, as in The Dark Jester, when the Dreamer's "unnerved [...] eyes heard the cry of the Bird":

I listened with new ears, new eyes, in my Dream. And I heard and saw the strange muted and muffled cry of the Bird in tones [...] that made me gasp. ${ }^{39}$

A remarkable feature of Harris's fiction is the coherence between content and form and their philosophical implications. As we have seen, his ap-

\footnotetext{
${ }^{34}$ See Wilson Harris, "A Note on the Genesis of The Guyana Quartet," in Harris, The Guyana Quartet (London: Faber \& Faber, 1985): 10.

${ }^{35}$ This expression is first used in The Eye of the Scarecrow and expresses the state of "negative identity" reached by the character who descends into the void of historical victims and into the deepest spaces of his own psyche.

${ }^{36}$ Wilson Harris, Companions of the Day and Night (London: Faber \& Faber, 1975): 13.

${ }^{37}$ Harris, Companions of the Day and Night, 59, 60. Pierre François suggests that the Fool himself is transmuted into Rain Emperor; François, Inlets of the Soul: Contemporary Fiction in English and the Myth of the Fall (Cross/Cultures 35; Amsterdam \& Atlanta GA: Rodopi, 1994), 266.

${ }^{38}$ Harris, Companions of the Day and Night, 77.

${ }^{39}$ Harris, The Dark Jester, 20-21.
} 
proaches to imagination as both instrument and object of quest are partial as are the multitudinous ways in which his characters move towards the "womb of space" or wholeness. And, as he pointed out and exemplifies in his narratives, "all the imageries are partial though attuned to a wholeness one can never seize or structure absolutely." wholeness which Harris deems "unfathomable," different from totality, which suggests a static absolute, whereas wholeness made of all human experience, all partial elements, all cultures, evolves constantly. Though unattainable as such, it has a life of its own as the expression "living text," mentioned above, suggests: "It is as if the text is alive in its own right, and the text has this capacity to revise itself. The text has an intention of its own." ${ }^{, 42}$ It manifests itself to the writer, who glimpses it intuitively and intermittently. ${ }^{43}$ Creation is therefore a two-directional process, a move towards and from the unconscious, while in their livingness the many parts of wholeness are susceptible to connections and links between each other:

We have a world that is tormented and torn and divided into all sorts of compartments, and the bridges between these cultures are very difficult to sustain. But they do exist. They can be found.

\section{And further:}

The dead change within our unconscious. The dead return as an aspect of the unfinished genesis. The dead return, therefore, in fiction, to carry a burden which apparently we cannot carry and at the same time we become aware of our deepest roots in nature. We become aware of those roots which are so deep that they hold out some kind of hope, as if what lies in the past can address us through the unfinished genesis of a certain kind of rhythm that animates spaces, architectures, and worlds. ${ }^{44}$

These deep-seated linkages are the foundation of Harris's cross-culturalism - a term which, I think, he was the first to use - and of his art. It should be noted, however, that in spite of his emphasis on the role of imagination and

\footnotetext{
${ }^{40}$ Harris, "The Unfinished Genesis of the Imagination," 74.

41 "All the structures are partial [...]. What relates these structures is an unnameable centre or unfathomable wholeness." "Wilson Harris - An Interview," by Helen Tiffin, New Literature Review 7 (1979): 24.

${ }^{42}$ Harris, "Originality and Tradition," in The Radical Imagination, 117.

${ }^{43}$ On this subject, see "Wilson Harris interviewed by Alan Riach," in The Radical Imagination, 33-65.

${ }^{44}$ Harris, "Creative and Re-Creative Balance Between Diverse Cultures," in The Radical Imagination, $114^{-15}$.
}

his explorations of the nature of art, particularly in The Dark Jester and The Mask of the Beggar, his world-view is at the opposite pole of the concept of art for art's sake. Art is life and creates a dialogue between the visible and the invisible, our material existence and the infinite, which is why, ultimately, "art transcends the material of which it is made [...]. [It] lies [...] in a consciousness of timelessness we cannot seize." root of art, which is also the unconscious, the abyss in which silent crowds move in Harris's fiction, has the capacity to secrete what Harris calls the "re-visionary potential within texts and imageries of reality. ${ }^{, 46}$ In most of his essays, Harris compares the power of imagination and art (but also of love and compassion) to stimulate social change with discoveries in science and their effect on communal and individual life. In The Mask of the Beggar, one of the characters meditates on the "Comedy of the Inferno" (the state of the world) in the following terms:

$$
\begin{aligned}
& \text { How had the Comedy of the Inferno come into being? } \\
& \text { [...] } \\
& \text { It had imposed itself upon us - those of us, let me say, who are deemed out- } \\
& \text { siders, racially inferior or disobedient in charting another faith, heretical or } \\
& \text { breakers of the law - wittingly, at times, unwittingly, at other times, by closures, } \\
& \text { a repetition of closures in language and in ideas adopted by politics, economics, } \\
& \text { and science, exercised therefore by a dominant civilization which sees itself as } \\
& \text { absolute in its values of communication. Such absolution breeds Death as the } \\
& \text { final machine or conquistador or creator of things to come. A restlessness com- } \\
& \text { mences amongst gods and artists who seek an openness to all fixtures of lan- } \\
& \text { guage that run contrary to innermost thought, to all closures and tyrannies of } \\
& \text { convention. }
\end{aligned}
$$

\section{WORKS CITED}

François, Pierre. Inlets of the Soul: Contemporary Fiction in English and the Myth of the Fall (Cross/Cultures 35; Amsterdam \& Atlanta G A: Rodopi, 1994).

Harris, Wilson. "The Age of the Imagination," Journal of Caribbean Literatures 2.1-3 (2000): 17-25

-. Ascent to Omai (London: Faber \& Faber, 1970).

- Companions of the Day and Night (London: Faber \& Faber, 1975).

. The Dark Jester (London: Faber \& Faber, 2001).

${ }^{45}$ Harris, The Dark Jester, 11-12.

${ }^{46}$ Harris, "The Fabric of the Imagination," 21.

${ }^{47}$ Wilson Harris, The Mask of the Beggar (London: Faber \& Faber, 2003): 64. 
- The Eye of the Scarecrow (London: Faber \& Faber, 1965).

."The Fabric of the Imagination," in From Commonwealth to Post-Colonial, ed. Anna Rutherford (Mundelstrup \& Sydney: Dangaroo, 1992): 18-29.

- The Far Journey of Oudin (London: Faber \& Faber, 1961).

History, Fable and Myth in the Caribbean and Guianas, intro. Selwyn R. Cudjoe (1970; Wellesley M A : Calaloux, 1995).

- The Infinite Rehearsal (London: Faber \& Faber, 1987).

- Jonestown (London: Faber \& Faber, 1996).

."The Landscape of Dreams," interview by Michael Gilkes, in Wilson Harris: The Uncompromising Imagination, ed. Hena Maes-Jelinek (Mundelstrup \& Sydney:

Dangaroo, 1991): $31-38$.

-The Mask of the Beggar (London: Faber \& Faber, 2003).

- . "A Note on the Genesis of The Guyana Quartet," in Harris, The Guyana Quartet

(London: Faber \& Faber, 1985): 7-14

- Palace of the Peacock (1960; London: Faber \& Faber, 1998)

- "Profiles of Myth and the New World," in Nationalism and Internationalism: (Inter) National Dimensions in Literatures in English, ed. Wolfgang Zach \& Ken L. Goodwin (Tübingen: Stauffenburg, 1996): 77-86.

The Radical Imagination: Lectures and Talks, ed. Alan Riach \& Mark Williams

(Liège: L3 - Liège Language and Literature, 1992).

- Resurrection at Sorrow Hill (London: Faber \& Faber, 1993).

The Secret Ladder (London: Faber \& Faber, 1963).

- Tradition the Writer and Society (London \& Port of Spain: New Beacon, 1967).

-. "The Unfinished Genesis of the Imagination," Temenos Academy Review 13 (1992): 69-85.

- "The Voyaging Imagination (Undreant-of Resources of Spirit)," unpublished manuscript (6 pp.).

. "When one dreams one dreams alone," Wilson Harris interviewed by Fred

D'Aguiar, Bomb 82 (Winter 2002-2003), 75-80.

The Whole Armour (London: Faber \& Faber, 1962).

_. "Wilson Harris - An Interview," by Helen Tiffin, New Literature Review 7 (1979): 24

- The Womb of Space: The Cross-Cultural Imagination (Westport CT: Greenwood, 1983).

Jagan, Cheddi. The West On Trial (Berlin: Seven Seas, 1975). 